\title{
Reflexões sobre possibilidades e desafios da educação popular como referencial para o trabalho de residentes em Medicina de Família e Comunidade
}

\author{
Bruno Oliveira Carreiro ${ }^{1}$, Pedro José Santos Carneiro Cruz ${ }^{2}$
}

\begin{abstract}
Resumo
O presente trabalho analisa possibilidades e desafios da Educação Popular (EP) como referencial para o trabalho médico no contexto da Residência de Medicina de Família e Comunidade. É um estudo do tipo compreensivo e interpretativo, realizado em João Pessoa, Paraíba, Brasil, com residentes do segundo ano da Residência de Medicina de Família e Comunidade, vinculada à Universidade Federal da Paraíba, por meio da metodologia de grupo de discussão. Os resultados evidenciaram potencialidades agregadas pela EP ao trabalho médico, como construção compartilhada de conhecimento, o trabalho integrado com agentes comunitários de saúde e com outros profissionais, bem como o estabelecimento dos grupos comunitários e das consultas médicas como espaços educativos. Emergiram obstáculos para a prática da EP como: pressão assistencial elevada e conflitos com modelos de gestão centrados preponderantemente na prestação de atendimento ambulatorial. Conclui-se que a EP é uma estratégia presente no cotidiano de trabalho dos residentes, mas sua implementação sofre dificuldades a serem superadas para real efetivação como ferramenta potencializadora do trabalho médico.
\end{abstract}

\section{Palavras-chave}

Educação Popular. Medicina de Família e Comunidade. Residência Médica. Atenção Primária à Saúde. Educação em Saúde.

\footnotetext{
${ }^{1}$ Mestrando do Programa de Pós-graduação em Educação, Trabalho e Inovação em Medicina, Universidade Federal do Rio Grande do Norte, Brasil; médico-área Medicina de Família e Comunidade, Escola Multicampi de Ciências Médicas do Rio Grande do Norte, Brasil. E-mail: bocarreiro@yahoo.com.br.

2 Doutor em Educação (Educação Popular) pela Universidade Federal da Paraíba, Brasil; professor da Universidade Federal da Paraíba, Brasil; líder do Grupo de Pesquisa em Extensão Popular - EXTELAR (CNPq/UFPB); membro da Coordenação do Grupo Temático (GT) de Educação Popular em Saúde da Associação Brasileira de Saúde Coletiva (ABRASCO) e membro da Comissão de Ciências Sociais e Humanas em Saúde. E-mail: pedrojosecruzpb@yahoo.com.br.
} 


\title{
Reflections on the possibilities and challenges of popular education as a reference for the work of Residents in Family and Community Medicine
}

\author{
Bruno Oliveira Carreiro ${ }^{3}$, Pedro José Santos Carneiro Cruz ${ }^{4}$
}

\begin{abstract}
This paper analyzes the possibilities and challenges of Popular Education (PE) as a reference for medical work in the context of the Family and Community Medicine Residence. It is a comprehensive and interpretive study conducted in João Pessoa, State of Paraíba, Brazil, with residents of the second year of the Family and Community Medicine Residency linked to the Federal University of Paraíba, through the group discussion methodology. The results evidenced PE's potential for medical work, such as shared knowledge construction, integrated work with community health agents and other professionals, as well as the establishment of community groups and medical consultations as educational spaces. Obstacles to the practice of PE emerged, such as: high care pressure and conflicts with management models that focused predominantly on outpatient care. It is concluded that PE is a strategy present in the daily work of the residents, but its implementation suffers difficulties to be overcome for real effectiveness as a tool for enhancing medical work.
\end{abstract}

\section{Keywords}

Popular Education. Family and Community Medicine. Medical Residency. Primary Health Care. Health Education.

\footnotetext{
${ }^{3}$ Master student of the Graduate Program in Education, Work and Innovation in Medicine, Federal University of Rio Grande do Norte, State of Rio Grande do Norte, Brazil; Doctor in the area of Family and Community Medicine, Multicampi School of Medical Sciences of Rio Grande do Norte, State of Rio Grande do Norte, Brazil. E-mail: bocarreiro@yahoo.com.br.

${ }^{4} \mathrm{PhD}$ in Education (Popular Education), Federal University of Paraíba, State of Paraíba, Brazil; professor at the Federal University of Paraíba, Brazil; leader of the Popular Extension Research Group - EXTELAR $(\mathrm{CNPq} / \mathrm{UFPB})$; member of the Coordination of the Thematic Group (WG) of Popular Health Education of the Brazilian Association of Collective Health (ABRASCO) and member of the Commission of Social and Human Sciences in Health. E-mail: pedrojosecruzpb@yahoo.com.br.
} 


\section{INTRODUÇÃO}

A Educação Popular (EP) é uma perspectiva político-pedagógica do fenômeno educativo desenvolvida pioneiramente na América Latina, tendo o Brasil um papel de destaque desde o final da década de 1950, por meio do trabalho do Serviço de Extensão Cultural da Universidade do Recife e de uma série significativa de iniciativas do Movimento de Cultura Popular. Nesse contexto, Paulo Freire e uma equipe de educadores passaram a se dedicar ao desafio de constituir experiências de educação de adultos das classes populares, baseando a construção do conhecimento e da aprendizagem a partir do educando (VASCONCELOS, 2011; PEREIRA; PEREIRA, 2010). Por essa perspectiva, enfatiza-se a realidade em que o educando está inserido, de modo a se produzir uma leitura crítica da realidade dos mais variados pontos de vista, seja social, político ou econômico, visando à emancipação dos indivíduos marginalizados e seu protagonismo social (VASCONCELOS, 2004; BRANDÃO, 1981).

No âmbito da Saúde, a EP foi valorizada a partir do Movimento pela Reforma Sanitária, nas décadas de 1970 e 1980, que originou práticas e organizações comunitárias para o fortalecimento do setor Saúde na perspectiva do direito, da equidade e da participação popular (VASCONCELOS, 2004). Esse movimento era contrário à política de saúde que valorizava a expansão de serviços médicos privados, os quais mantinham forte ênfase curativista e colocavam ações de saúde pautadas em atividades educativas em segundo plano.

Dessa forma, as ações de saúde comunitária associaram-se a setores progressistas da Igreja Católica, construindo experiências em saúde não vinculadas ao Estado, passando a identificar as classes subalternas não como sinônimo de ignorância ou de massa incapaz de pensar a própria realidade, mas como pessoas, grupos e coletivos que tinham saberes e fazeres úteis para a construção de processos de reorientação das práticas de saúde (VASCONCELOS; VASCONCELOS, 2012).

Com a criação do Sistema Único de Saúde (SUS) e seu desenvolvimento, as ações e serviços públicos de saúde no Brasil passaram a ser organizados em diferentes níveis de atenção: primária, secundária e terciária (VASCONCELOS, 2004). Segundo Harzheim e Mendonça (2013), a Atenção Primária à Saúde (APS) passa a se destacar por ser porta de entrada ao sistema de saúde, promovendo cuidados aos indivíduos, famílias e comunidades e por articular o cuidado integral por intermédio de equipe multiprofissional, e coordenando o 
acesso a outros níveis do sistema, seguindo seus atributos essenciais e derivados definidos internacionalmente por Starfield (2002).

Nesse contexto de expansão da APS no Brasil, a Medicina de Família e Comunidade (MFC) se fortalece por ser uma especialidade voltada para os princípios propostos por Starfield (2002), como integralidade, coordenação do cuidado, longitudinalidade, contextualização do ponto de vista familiar e comunitário (ANDERSON; GUSSO; CASTRO FILHO, 2005); e por dialogar com os princípios doutrinários e organizativos do SUS, como universalidade, equidade, integralidade e participação popular (BRASIL, 1990). A EP, por sua vez, passa a ser bastante estudada no contexto da APS, dando ênfase ao trabalho comunitário, participação social e protagonismo das classes menos favorecidas, especialmente a partir dos trabalhos de Vasconcelos (2015).

Por ser a Residência Médica uma etapa de formação, consideramos importante abordar a questão de como está posta a EP na formação do profissional médico. Sabe-se que o médicoresidente é um profissional em formação e que atua com a responsabilidade de executar as ações em saúde o mais próximo possível do ideal. Como a Medicina de Família e Comunidade é, por excelência, a especialidade médica voltada para a APS, o médicoresidente constitui-se em um profissional relevante para o entendimento de como a prática da EP se constrói no exercício diário da profissão do médico de família e comunidade.

O objetivo deste trabalho foi investigar as relações que a EP pode ter com o cotidiano do trabalho médico no contexto da Residência de Medicina de Família e Comunidade, abordando concepções e práticas entre os residentes de MFC, obstáculos e dificuldades de implantação da EP no cotidiano de trabalho médico na residência, potencialidades encontradas para o exercício da EP nas atividades diárias e perspectivas para a consolidação da EP no dia a dia do médico residente.

Pesquisas dessa natureza poderão contribuir para o campo da saúde coletiva, principalmente no que diz respeito ao contexto de trabalho e suas relações com a EP no contexto da Residência Médica dos diversos programas de Medicina de Família e Comunidade presentes no país, fornecendo maior subsídio teórico para investigações posteriores que venham a ser realizadas. 


\title{
METODOLOGIA
}

\author{
Tipo de estudo
}

Este estudo constituiu-se do tipo qualitativo, tendo, portanto, ênfase compreensiva e interpretativa. Buscou-se analisar concepções, relações entre o agir e o pensar para evidenciar modos de superar as contradições que porventura possam existir entre a prática de trabalho do médico residente e a EP, uma vez que ambas devem estar em consonância para viabilizar e garantir a prestação do cuidado em saúde no nível da APS.

\section{Local e sujeitos do estudo}

O estudo foi realizado em João Pessoa-PB, no contexto da Residência de Medicina de Família

e Comunidade, vinculada ao Hospital Universitário Lauro Wanderley da Universidade Federal da Paraíba, que é a instituição responsável pela formação teórica dos residentes e que se constituiu em local de encontro semanal para discussão de atividades teóricas da residência médica em MFC. Os sujeitos do estudo foram os residentes de Medicina de Família e Comunidade que cursavam o segundo ano de residência. Optou-se por esses residentes por possuírem maior tempo de prática e vivências mais aprofundadas a respeito da prática médica enquanto residentes, da própria EP e de suas relações com o cotidiano de trabalho.

\section{Produção do material empírico}

A produção de material empírico foi realizada a partir de entrevistas semiestruturadas, baseadas na metodologia do grupo de discussão, com os residentes em um único grupo, com duração de uma hora e meia. Grupo de discussão é uma prática metodológica de pesquisa qualitativa que permite a produção de material a partir do diálogo dos participantes sobre questões propostas, tendo um ou mais moderadores que conduzem o debate; ele pode apresentar maior ou menor influência sobre o grupo, dependendo do tipo de situação discursiva tratada (GODOI, 2015).

O papel de moderador foi assumido pelos autores deste trabalho, sendo realizado contato com cada um dos residentes e convite para a participação do grupo. Um roteiro foi utilizado com perguntas abertas, com a finalidade de produzir material para a análise do conteúdo, tendo em 
vista os objetivos propostos, e um gravador para melhor apreensão do conteúdo das entrevistas.

As questões propostas foram: quais as concepções de EP? Quais práticas orientadas pela EP são vivenciadas em seu cotidiano como residentes? Quais os principais desafios e obstáculos para a aplicabilidade dos princípios da EP na prática do trabalho médico enquanto residentes? Quais as principais potencialidades e possibilidades para a aplicabilidade dos princípios da EP na prática do trabalho médico enquanto residentes? Em que medida seus contextos de trabalho permitem a construção de práticas de saúde firmadas na EP? Quais sugestões para a melhoria do contexto laboral para a prática da EP no cotidiano da residência podem ser apontadas?

Cumpre destacar que este estudo atendeu aos requisitos propostos pela Resolução $\mathrm{n}^{\circ}$ 466/2012, do Conselho Nacional de Saúde, que dispõe sobre as normas e diretrizes regulamentadoras da pesquisa envolvendo os seres humanos. A pesquisa foi registrada no Comitê de Ética e Pesquisa sob número de CAAE: 80194217.9.0000.8069. As informações obtidas com a pesquisa foram gravadas e utilizadas nesse artigo, ressaltando que a identidade dos entrevistados não foi revelada.

\section{Análise dos dados}

A análise do material empírico pautou-se pela perspectiva da análise de conteúdo (BARDIN, 2009). Foi realizada após a transcrição das entrevistas gravadas, que formou o corpus documental. Tal corpus passou por uma sucessão de leituras analíticas, nas quais o pesquisador buscou a compreensão e interpretação do material. O plano de análise exigiu algumas etapas: leitura superficial das entrevistas, seguida pelo aprofundamento em conceitos expressos sobre a concepção e práticas dos residentes sobre a EP, obstáculos e dificuldades encontradas no cotidiano de trabalho, além de desafios e sugestões.

Posteriormente, seguiu-se a fase de exploração do material empírico que permitiu realizar uma operação classificatória, com objetivo de desvelar os núcleos temáticos de compreensão do texto. A análise criteriosa do material empírico obtido e distribuído nas categorias temáticas construídas serviu para mediar o confronto com a literatura atual sobre a temática, por meio de mecanismo de inferência, interpretação e articulação com o referencial teórico 
que fundamentou a pesquisa (BARDIN, 2009). As análises feitas responderam aos objetivos propostos.

\section{RESULTADOS}

Situando o contexto de prática dos médicos residentes

O Programa de Residência Médica em Medicina de Família e Comunidade, pertencente à Universidade Federal da Paraíba/Hospital Universitário Lauro Wanderley, está vinculado à Secretaria Municipal de Saúde de João Pessoa. O município conta com população recenseada de 723.515, em 2010, e estimada em 811.598 pessoas em 2017 (BRASIL, 2011a; BRASIL, 2017). Do ponto de vista da saúde, a cobertura da Estratégia Saúde da Família (ESF) é estimada entre 90 e 100\% de população atendida em Unidades de Saúde da Família (USF), com aproximadamente duzentas equipes de saúde da família, constituindo-se em um dos maiores índices de cobertura do país entre as capitais.

Desse total de equipes de saúde, sessenta são compostas por profissionais residentes em MFC, distribuídas em quatro instituições formadoras: Centro Universitário de Ensino (Unipê), Faculdade de Medicina do Nordeste (FAMENE), Faculdade de Ciências Médicas da Paraíba (FCM-PB) e Universidade Federal da Paraíba (UFPB).

Em sua totalidade, os residentes compõem equipe de saúde da família, não existindo nenhum caso em que o residente acompanhe médico de família.

A Residência Médica vinculada à UFPB encontra-se inserida em sete Unidades de Saúde da Família (USF). Todas funcionam de maneira integrada, ou seja, contendo mais de uma equipe de saúde orientada pela ESF, distribuídas em três distritos sanitários, sendo eles 1, 2 e 5. Em outubro de 2017, contava com vinte e seis residentes no total, sendo dezesseis em seu primeiro e dez incluindo o autor do estudo, em seu segundo ano de especialização. Possui seis médicos preceptores em seis USF distintas, em uma proporção de um preceptor para cada quatro a cinco residentes.

Os residentes que compõem a equipe de saúde da família ou estão sozinhos ou dividindo a mesma equipe de saúde com outro residente; neste último caso, em quatro equipes de saúde; em duas dessas equipes, dois residentes de segundo ano as compõem, ao passo que, nas outras duas, ocorre uma mescla de um de primeiro ano com outro de segundo ano. A rotina de 
trabalho dos residentes é constituída por oito turnos em atividades relacionadas à USF, um turno de aula teórica e outro de imersão em ambulatório de especialidades. A carga horária é complementada por um plantão semanal e oito horas destinadas à elaboração do Trabalho de Conclusão de Curso (TCC).

Os turnos destinados à APS são divididos em consultas individuais, por meio de atendimento à demanda espontânea, pré-natal, visita domiciliar, puericultura ou outra atividade que o residente decida criar; atividades de grupo, territorialização e reunião semanal da equipe de saúde. São realizados grupos diversos como de Hipertensão Arterial, Diabetes Melito, Saúde Mental, Tabagismo, Grupo de Mulheres, Grupo de Homens, Pré-Natal coletivo, a depender do contexto de trabalho especificado.

A preceptoria é realizada por médicos de família e comunidade contratados pela Secretaria Municipal de Saúde de João Pessoa e professores da UFPB, divididos entre preceptoria de campo e núcleo: a primeira é efetuada por um docente médico de família e comunidade ou que tenha concluído a residência em Medicina Preventiva e Social; a segunda, por docente com formação na área da saúde, como enfermagem, nutrição, psicologia, entre outros, com ênfase nos aspectos essenciais da saúde coletiva (gestão, planejamento, avaliação, vigilância, epidemiologia, participação social, educação em saúde, entre outros).

Além disso, docentes da UFPB que têm atuação nas USF por meio dos Módulos Horizontais A 1, 2, 4 e 5, também atuam como preceptores, os quais constituem componentes obrigatórios dos discentes da graduação de Medicina. Como há contato com esses professores, e eles, em diversas ocasiões, assessoram os residentes, terminam por participar do processo de formação e ensino.

\section{Dimensões da EP na prática do residente em $M F C$}

Dos nove residentes convidados para o grupo de discussão (uma vez que, como dito anteriormente dos $10 \mathrm{R} 2$, um era pesquisador e, portanto não concedeu entrevista), quatro compareceram, tendo sido obtidos os dados com estes residentes. Os resultados descritos no quadro 1 foram divididos em quatro seções e intercalados com trechos mais relevantes das falas dos residentes:

Quadro 1 - Trechos das entrevistas dos residentes que ilustram as categorias abordadas no estudo 


\section{Categorias}

Dimensões da EP e práticas no cotidiano

\section{Trechos das entrevistas}

"Troca de saberes, construção compartilhada de Conhecimento".

"Os grupos são onde a gente mais faz essa troca, essa partilha".

"As mulheres participantes do grupo de mulheres comentam 'É muito bom ter uma doutora que tá aqui com a gente, em roda, não tá como superior"'.

"Elas se sentem parte, se sentem importante quando a gente pergunta a elas o que elas querem discutir".

Obstáculos para aplicabilidade dos “Tem também a questão da pressão assistencial, princípios da EP da demanda, e... um turno inteiro não dá pra gente destinar ao grupo".

“Às vezes, a própria equipe não acha importante o médico sair do consultório e ir no grupo, ficar em roda. A equipe enxerga o grupo como horário de não atendimento".

"Os profissionais de saúde estão ali pra fazer o que têm que fazer somente, isso quando faz, e qualquer demanda a mais é vista como um pesadelo".

"Os usuários falam 'Ah se a senhora não souber, quem é que sabe? Eu vim pra saber do que tenho"".

“A enfermeira acredita que tá só dando uma ajudinha no atendimento da demanda espontânea, e, não, que é tarefa dela”.

Potencialidades para aplicabilidade dos princípios da EP

"Acho que só com a residência é que a gente tem esse apoio, porque com a gerência não tem, com os usuários às vezes não tem”.

"No início, a Residência foi muito importante, principalmente com os preceptores pra puxar as atividades que envolvem educação popular". 
Desafios e sugestões para aplicabilidade dos princípios da EP
"Quando é grupo de mulheres para abordar sexualidade, não dá pra fazer no hall, por exemplo".

"Os trabalhadores reclamam muito que antes a gestão dava lanche, hoje em dia nem a água do grupo ela dá”.

"Hoje em dia tem que tirar tudo do bolso"

"Um desejo era que onde houvesse residência médica, existisse também residência em odontologia, enfermagem, nutrição, para que se pudesse purificar a formação enquanto residentes".

Fonte: Arquivo pessoal dos autores (2018).

Os principais comentários referiram-se ao entendimento da EP como construção compartilhada de conhecimento, respeitando os diferentes saberes, principalmente o saber popular. Isso foi referido na consulta individual através do compartilhamento do plano terapêutico e pela possibilidade de autonomia aos usuários para que eles se empoderem sobre processos vividos no seu cotidiano, permitindo olhar integral sobre o ser humano.

Os principais espaços de prática da EP relatados foram os grupos realizados com a comunidade, sejam de pré-natal coletivo, puericultura, saúde mental, grupo de mulheres, Hipertensão Arterial Sistêmica, Diabetes Melito, que trabalham com metodologia participativa. Além disso, a própria consulta médica e a Terapia Comunitária Integrativa (TCI) também foram identificadas como espaço de práticas de EP.

\section{Obstáculos na prática da EP}

Os obstáculos relatados pelos residentes para a prática da EP no cotidiano foram: existência de pressão assistencial elevada com adstrição das áreas maior que a sugerida pelo Ministério da Saúde, conflitos e cobranças com a gerência da USF para prestar atendimento em consultório, e não se ausentar dela; pouco entendimento sobre o que é o cuidado regido sob a ótica da EP.

Houve relato também de pouca estrutura da USF para espaços de grupos, que permitam a própria reunião das pessoas ou maior privacidade para expressão de opiniões ou o exame 
físico dos usuários, a exemplo do pré-natal coletivo, ou falta de insumos para os grupos, como colchonetes, alimentação etc.

Além disso, relatou-se pouco reconhecimento da equipe de saúde sobre a importância da EP no processo de cuidado fora do consultório, sendo recorrente a fala de que lugar de médico é no consultório. Foi também evidenciado escasso envolvimento da equipe de saúde por precarização do trabalho na APS, desestímulo dos profissionais, muitas vezes formados em processos pedagógicos tradicionais, que não estimulam o diálogo, ou pelo próprio desinteresse de trabalhar na APS.

Foi ressaltado o fato de os pacientes não serem acostumados ao Método Clínico Centrado na Pessoa (MCCP), especialmente nos quesitos de compartilhamento de projeto terapêutico ou de entendimento do que é a doença.

Em relação ao processo de trabalho, evidenciou-se o fato de o cuidado na Atenção Primária ainda ser centrado no médico e pouco compartilhado com outros profissionais. Por fim, foi destacado o momento político após o impeachment da presidenta Dilma Rousseff, em 2016, de corte no financiamento para a saúde, para as políticas sociais, com perda de prioridade da gestão federal para a APS, com ênfase cada vez maior a atendimentos individuais, dificultando práticas de trabalho voltadas para a promoção e prevenção na saúde.

\section{Potencialidades para a prática da EP}

Foram apontadas como potencialidades: estar na Residência Médica, ter contato com preceptores já acostumados a trabalhar com a EP, trabalhar com ACS atuantes e com a RMSF.

Foi ressaltada a divisão de tarefas e demandas que surgem principalmente nos grupos e que são articuladas com os residentes multiprofissionais, e como eles ajudam no processo de trabalho. Levantou-se como potencialidade dividir a equipe de saúde com outro médico residente.

Por sua vez, foi referido que o formato de Residência Médica em MFC praticado pela UFPB pressupõe autonomia do residente no processo formativo, incluindo seu protagonismo e responsabilização em toda a conjuntura do processo de trabalho referente a diálogo com 
gerência de USF, sensibilização dos outros trabalhadores da equipe quanto à relevância da EP no dia a dia e disputas de espaços de atuação enquanto médico-residente.

\section{Desafios e sugestões para a prática da EP}

Entre os desafios e sugestões para aplicabilidade dos princípios da EP, foram relatados melhora da estrutura física da USF na qual a residência médica atua, com espaços de maior privacidade, insumos para grupos, além da pactuação com equipes de saúde e gerência da USF quanto a esclarecimento sobre o que é APS, acolhimento, quais os fluxos de atendimento.

Foi referida a possibilidade de atuação em USF compostas por equipes de saúde com residentes multiprofissionais de forma exclusiva. Outro desafio levantado foi a residência médica assumir protagonismo sobre a gerência em relação aos processos de $\mathrm{EP}$, tendo mais autonomia frente à gestão municipal.

\section{DISCUSSÃO}

A EP é uma estratégia imbricada nos princípios da Medicina de Família e Comunidade, tratando-se de um componente essencial no que diz respeito à abordagem comunitária de acordo com a Sociedade Brasileira de Medicina de Família e Comunidade (2015). Dominar os seus pilares é, pois, fundamental para o médico de família e comunidade exercer um cuidado adequado aos seus usuários, do ponto de vista integral, com ênfase em suas necessidades, de modo a se voltar para a pessoa que procura assistência à saúde e a transformação de sua realidade.

As concepções de EP identificadas evidenciaram, parcialmente, associação entre os seus preceitos e a prática cotidiana dos residentes, uma vez que estiveram relacionadas à construção compartilhada do conhecimento, com respeito ao diálogo, saber popular, problematizando a realidade a partir da experiência dos usuários. A APS rejeita o modelo biomédico tradicional, flexneriano, centrado em doenças, e aponta para um modelo de saúde centrado nas pessoas, que busca a integralidade no cuidado à saúde de indivíduos e coletividades (BRASIL, 2011b). Nesse sentido, dialoga fortemente com a EP, à medida em que ambas defendem a construção de saúde integral, que perpasse pelos contextos econômico, político, social, cultural, religioso, familiar, atendendo à integralidade, orientação familiar e 
comunitária. Outra intersecção observada ocorre durante o processo de adoecimento, quando as pessoas se fragilizam e passam então a questionar aspectos subjetivos e objetivos de seu modo de viver até então; nesse momento, a EP torna-se fundamental para auxiliar esse processo de reflexão, possibilitando mudanças de comportamentos que antes eram pouco questionados (VASCONCELOS; VASCONCELOS, 2012).

As consultas individuais foram destacadas como potencial de desenvolvimento e aprimoramento da EP no trabalho do residente. Na visão dos entrevistados, isso ocorre em especial pelo atitude de construção compartilhada do processo terapêutico, o que coaduna com os preceitos do Método Clínico Centrado na Pessoa (MCCP). O MCCP é uma ferramenta de abordagem clínica da MFC baseada nas necessidades das pessoas que procuram atendimento, apresentando quatro componentes: explorar a experiência da pessoa com a doença, entender a pessoa como um todo em seus diferentes contextos, elaborar um plano de cuidado comum ao médico e à pessoa para manejar os problemas e intensificar a relação médico-pessoa (LOPES, 2015; STEWART, 2014).

À medida que a EP estimula o entendimento dos diversos contextos que cercam os indivíduos e produz reflexão compartilhada sobre o que acomete as pessoas e incentiva debates sobre questões que lhe afetam, percebe-se uma dimensão potente no encontro entre a perspectiva da EP e a metodologia do MCCP. Pode-se, dessa forma, permitir ao residente exercitar e aprimorar uma abordagem de cuidado com base na análise crítica da realidade, partindo das situações vivenciadas pelos usuários em seu cotidiano, que passam a se identificar como agentes relevantes dentro da consulta médica. O MCCP também faz intersecção com a EP quando, na construção do projeto terapêutico, defende um processo de discussão que não seja imposto, mas, ao contrário, que seja dialogado, horizontalizado. Além disso, os espaços de prática identificados pelos residentes também corroboram com o proposto pela $\mathrm{EP}$, sendo o seu uso em grupos uma das potencialidades para a APS (GOMES; MERHY, 2011).

Por outro lado, não foram abordados abertamente, ao longo das entrevistas, aspectos relevantes da EP, como emancipação política dos sujeitos menos favorecidos, leitura crítica e transformação social da realidade, seja durante as consultas médicas ou na participação em grupos. Comenta-se em dar voz e vez aos indivíduos, na importância do diálogo na constituição desses espaços de práticas de EP, no entanto, a percepção ainda ocorre sem tal direcionamento, fundamental para o exercício da EP. 
Nessa direção, os espaços de prática de EP não evidenciaram, durante as entrevistas, outras possibilidades de atuação, como os conselhos locais de saúde, reuniões de equipe, educação permanente em saúde, o próprio acolhimento. Isso sugere ausência de participação dos residentes nesses cenários ou não identificação desses espaços como possibilidades de atuação pautados nos princípios da EP. Trata-se de uma fragilidade considerável uma vez que participar, entender o funcionamento, envolver a população nos debates em torno da vida comunitária e estimular a participação social são elementos chave na formação do médico de família e comunidade e na defesa do SUS (CAMPOS, 2005).

Percebe-se pouca identificação da EP com o processo de trabalho da equipe. Isso sugere percepção reduzida das possibilidades de atuação da EP, com parca importância dada ao desenvolvimento do processo de trabalho. Tal observação induz à formação incompleta do médico de família e comunidade, uma vez que o trabalho em equipe e a implantação da EP no cotidiano de trabalho são tarefas importantes desse especialista.

Os obstáculos expostos pelos residentes evidenciaram um largo caminho para que possamos atingir condições ideais para o desenvolvimento da EP no contexto de trabalho da Residência em MFC. A pressão assistencial está diretamente relacionada ao tamanho da clientela de uma equipe de saúde, sendo determinante para a condução do seu processo de trabalho. Sabe-se que, nesse ambiente formativo, a adscrição de um território em que atuem médico-residentes em MFC compondo a equipe de saúde da família deve conter, idealmente, 2.000 mil usuários (BRASIL, 2015). A análise dos depoimentos revela que, nos contextos em que tal condição não é respeitada, os residentes alegam mais dificuldades para dispor de tempo e de tranquilidade para planejar e promover atividades orientadas pela EP, com pouca oferta de outras ações para além do consultório médico. Além disso, mesmo a inserção da EP na atividade de trabalho mais frequente (a consulta médica) fica fragilizada, uma vez que a pressão assistencial amentada traz consigo elementos como tensões, conflitos e dificuldade de relacionamento com a equipe e com a comunidade. Nessa trilha, relatou-se pelos participantes da pesquisa uma tendência de se conduzir a consulta médica individual no formato queixaconduta, desvinculada do MCCP.

Ampliando o olhar sobre esses obstáculos, não é apenas o número de usuários adscritos que dificulta o desenvolvimento da EP. É necessário considerar que é um desafio premente na realidade do SUS o estabelecimento de uma agenda de serviços e de ações que extrapole a exclusividade da dimensão assistencial e a articule com dimensões da saúde como a 
prevenção, a promoção e os processos educativos coletivos em saúde (VASCONCELOS, PRADO, 2017; BOTELHO et al., 2018). O modelo de formação flexneriano, com ênfase em uma visão biomédica do processo saúde e doença, ainda é muito presente na ação de muitos profissionais de saúde atuantes no SUS (VASCONCELOS, 2015). Ademais, em muitos casos a necessidade de resultados políticos imediatos leva gestões do SUS a cobrar e valorizar, preponderantemente, a produção assistencial ambulatorial, mesmo no âmbito da APS. Finalmente, muitos setores da população ainda preferem e demandam abordagens profissionais de cunho prescritivo e centrado na doença.

A participação ainda tímida das pessoas da comunidade em algumas iniciativa de EP é apontada por Cruz (2015). Para o autor, ainda é tímido o envolvimento dos usuários em reuniões e rodas de conversa em que a participação dos moradores seja voluntária e exija que todos saiam de suas casas. Nessa questão, percebe-se também, em alguns casos, pouco comprometimento tanto dos grupos sociais territorializados quanto dos profissionais da USF em participar assiduamente das reuniões, o que gera desmotivação. Muitos sujeitos da comunidade também participavam pouco, ou sequer se fazem presentes, porque esperam do setor saúde apenas abordagens diretivas e curativas, com intervenções tradicionais como prescrição de condutas e tratamentos. Para alguns setores da população, as reuniões das ações de EP constituem momentos de insatisfação e "conversa jogada fora", com pouca resolução de "problemas de saúde". Para essas pessoas, questões contextuais e estruturais (muito abordadas pelas práticas de EP) deveriam ser tratadas apenas pelo poder público e pelos “políticos” (CRUZ, 2015).

Falta de estrutura física e de insumos associados a descompassos entre gerentes e residência médica levam à perda da qualidade do ambiente formativo, haja vista tempo e esforço que serão gastos para o convencimento dos gestores da importância da EP e de locais apropriados para sua prática na USF.

Sabe-se que condições estruturais adequadas são de extrema importância para a produtividade do ambiente de trabalho, assim como satisfação e bem-estar dos trabalhadores (FERNANDES, 1996; MILANEZ et al., 2018; SORATTO et al., 2017). Apesar dos avanços nas políticas públicas, no campo da Saúde da Família, muitas equipes convivem com dificuldades de infraestrutura para realização de suas ações. Além disso, os trabalhadores convivem com situações precarizadas de vínculo, remuneração salarial e de condições de trabalho. No dia a dia, muitas ações e metas não são pactuadas no interior da equipe e suas 
reuniões, mas provêm de demandas do nível central da gestão de saúde municipal, ou mesmo do Ministério da Saúde, o que impõe aos trabalhadores dificuldades para sustentar minimamente um planejamento de suas ações com respeito e valorização das atividades locais e territoriais (CRUZ, 2015).

Equipes de saúde profissionalmente desestimuladas (PEGORARO; SCHAEFER; ZOBOLI, 2017) e que convivem com imposições de metas para o desenvolvimento de seus trabalhos encontram obstáculos importantes para a atuação com práticas orientadas pela EP, a qual pode ser ferramenta fundamental para sua constituição enquanto profissional.

Conforme pontua Cruz (2015), há de se observar, contudo, que, muitas vezes, o cotidiano desafiador e a realidade do trabalho em saúde da família podem constituir como justificativas para a pouca disposição de alguns trabalhadores não participarem nas atividades de EP. Como ressalta o autor, muitos trabalhadores preferem ficar na "mesmice", em lugar de colaborar com a construção de ações de educação em saúde com caráter participativo e comunitário.

Outro desafio para a EP nesse contexto reside nos limites ainda encontrados para o processo de desenvolvimento da concepção da MFC no Brasil. Mesmo em experiências como a dos residentes entrevistados, nas quais a Residência é desenvolvida há anos, situações como o compartilhamento de planos terapêuticos causam estranheza aos usuários. Uma vez que esse é um elemento fundamental para a prática dos médicos de família e comunidade, pode-se concluir que a MFC encontra obstáculos para o desenvolvimento de sua essência, e isso constitui outro desafio para a prática da EP, especialmente ao considerarmos ser central para essa concepção o protagonismo das pessoas em seus processos de cuidado, bem como a ênfase do profissional nas especificidades das pessoas, o que constitui exigência do MCCP, o qual configura elemento fundamental na formação desse profissional em MFC.

É imprescindível para o aprimoramento da APS políticas de incentivo federal que objetivem sua expansão e qualificação. Desde 2016, observou-se retração da APS, com perda de financiamento, redução de vagas no Programa Mais Médicos, ameaça de extinção do SUS, ou de instituição do chamado plano popular de saúde, redução de financiamento para políticas sociais que reverberam no setor de saúde brasileiro. Desde então, a ênfase do Governo Federal tem focado em interesses mercadológicos, pautados pela submissão aos parceiros comerciais do Norte especialmente, distanciando-se de políticas democráticas e participativas (FERNANDES, 2017). 
As potencialidades apontadas na pesquisa evidenciaram a importância do ambiente formativo para a aplicabilidade da EP em saúde, seja através dos residentes multiprofissionais ou da Residência Médica em MFC. Como indicado nos resultados, se o formato de Residência Médica com autonomia do residente no processo formativo, incluindo seu protagonismo e responsabilização, constitui uma potencialidade por mobilizar o médico a desvelar processos de aprendizagem na prática, exercitando habilidades de resolução de problemas e de pactuação de planejamento e de experiências, por outro lado, constitui um desafio à medida em que, muitas vezes, o residente encontra pouco apoio para mediar os conflitos da conjuntura do processo de trabalho e articular os outros trabalhadores da equipe quanto à relevância da EP no dia a dia.

Ao mesmo tempo em que foi identificada a Residência Médica como potencialidade para a aplicabilidade dos princípios da EP, foi também evidenciada como desafio, na medida em que ela deve estar presente na construção dessas práticas, seja para inserir os residentes nas equipes de saúde da família com população adscrita próxima ao ideal, com menor pressão assistencial; articular com gerentes a abertura de espaços na agenda de trabalho para participação do residente em práticas de EP, dialogando sobre o papel do médico de família frente à comunidade, ratificando o momento de aprendizado no qual os residentes se encontram.

Por fim, outros desafios ressaltaram a necessidade de insumos para a realização dos grupos. Um dos grandes motivadores para a mudança de patamar do Programa de Residência em Medicina de Família e Comunidade, vinculado à Secretaria Municipal de Saúde do Rio de Janeiro, foi a reestruturação das Unidades Básicas de Saúde em Clínicas de Família com farto aparato de salas, prontuário eletrônico, auditórios, ar condicionado, acesso à internet, reconstruindo a APS em âmbito municipal (JUSTINO; OLIVER; MELO, 2016). Semelhantemente, para que a EP possa se fortalecer enquanto prática cotidiana de trabalho, é necessário disponibilidade de itens nas USF ou, se fora delas, disponíveis aos trabalhadores de modo que se possa exercer atividades com qualidade, regidas pelos princípios da EP.

\section{CONSIDERAÇÕES FINAIS}

Considerando os objetivos deste artigo de analisar a EP no cotidiano de trabalho do médico residente, conclui-se que essa constitui uma estratégia potente, principalmente por meio da 
ação com grupos comunitários e com abordagens participativas e dialógicas em consultas individuais, sobretudo pela perspectiva da construção compartilhada de conhecimento. Ademais, o trabalho integrado com agentes comunitários de saúde e com outros profissionais de saúde destaca-se como elemento potencializador mobilizado pelas ações em EP.

Dentre os obstáculos para essa perspectiva educativa no contexto da APS, identificou-se a elevada pressão assistencial e os conflitos mediante cobranças de setores da gestão em saúde no sentido desse profissional dedicar-se centralmente ao âmbito do consultório. Houve relatos de fragilidades da estrutura das USF para espaços de grupos ou falta de insumos para os mesmos. Entre os desafios, evidenciou-se a necessidade de aprimorar a compreensão da equipe interprofissional de trabalhadores nas USF sobre a concepção e a aplicabilidade dos princípios da EP no cotidiano da APS, como também, tanto na gestão das residências como dos serviços de saúde, constituir uma compreensão de que a prática médica precisa ser desenvolvida em outros espaços sociais, que não apenas no consultório ambulatorial.

A EP é uma estratégia possível para o cotidiano de trabalho dos residentes em MFC, mas sua implementação exige enfrentamento de desafios e de dificuldades para sua real efetivação enquanto ferramenta potencializadora do trabalho médico

\section{REFERÊNCIAS}

ANDERSON, M. I. P.; GUSSO, G.; CASTRO FILHO, E. D. Medicina de Família e Comunidade: especialistas em integralidade. Revista APS, Rio de Janeiro, v. 8, n. 1, p. 61-67, jan./jun. 2005. Doi: 10.5712/rbmfc9(30)850.

BARDIN, L. Análise de conteúdo. Lisboa: Editora 70, 2009.

BOTELHO, B. O. et al. Educação popular no sistema único de saúde. São Paulo: Hucitec, 2018. 303 p.

BRANDÃO, C. R. O que é educação popular. São Paulo: Brasiliense, 1981.

BRASIL. Conselho Nacional de Secretários de Saúde. Atenção Primária e Promoção da Saúde. Brasília: CONASS, 2011b. 197 p.

BRASIL. Instituto Brasileiro de Geografia e Estatística. Censo Demográfico 2010.

Características da população e dos domicílios: resultados do universo. Rio de Janeiro: IBGE, 2011a.

BRASIL. Instituto Brasileiro de Geografia e Estatística. Estimativas da população residente com data de referência $1^{\circ}$ de julho de 2017. Disponível em https://biblioteca.ibge.gov.br/visualizacao/livros/liv100923.pdf. Acesso em: 10 mar. 2019. 
BRASIL. Lei no 8.080, de 19 de setembro de 1990. Lei Orgânica da Saúde. Dispõe sobre as condições para a promoção, proteção e recuperação da saúde, a organização e o funcionamento dos serviços correspondentes e dá outras providências. Diário Oficial da União, Brasília, DF, 20 set. 1990.

BRASIL. Ministério da Educação. Secretaria De Educação Superior. Comissão Nacional de Residência Médica. Resolução no 1, de 25 de Maio de 2015. Regulamenta os requisitos mínimos dos programas de residência médica em Medicina Geral de Família e Comunidade R1 e R2 e dá outras providências. Diário Oficial da União, Brasília, DF, 26 maio 2015.

CAMPOS, C. E. A. Os princípios da medicina de família e comunidade. Revista APS, Rio de Janeiro, v. 8, n. 2, p. 181-190, jul./dez. 2005. Disponível em: http://www.ufjf.br/nates/files/2009/12/principios.pdf. Acesso em: 10 fev. 2019.

CRUZ, P. J. S. C. Agir crítico em nutrição: uma construção pela educação popular. 2015. 393 f. Tese (Doutorado) - Programa de Pós-graduação em Educação, Universidade Federal da Paraíba, João Pessoa. 2015.

DAMNO, H. S. et al. Perfil profissional dos médicos atuantes na Estratégia Saúde da Família no município de Campo Grande- MS. Encontro: Revista de Psicologia, Londrina, v. 16, n. 25, p. 125-137, 2013. Disponível em:

https://revista.pgsskroton.com/index.php/renc/article/view/2437. Acesso em: 10 fev. 2019.

FERNANDES, E. C. Qualidade de vida no trabalho. Salvador: Casa da Qualidade, 1996.

FERNANDES, J. S. O Brasil e a saúde pública internacional: uma análise das conexões entre o doméstico e o internacional. In: ENCONTRO NACIONAL DA ABRI: ESTUDOS SOBRE HISTÓRIA DAS RELAÇÕES INTERNACIONAIS E DA POLÍTICA EXTERNA, 6., 2017, Belo Horizonte. Anais [...]. Belo Horizonte: ABRI, 2017. p. 2-16.

GODOI, C. K. Grupo de discussão como prática de pesquisa em estudos organizacionais. Rev. Adm. Empres., São Paulo, v. 55, n. 6, p. 632-644, dez. 2015. Doi: 10.1590/S0034759020150603.

GOMES, L. B.; MERHY, E. E. Compreendendo a educação popular em saúde: um estudo na literatura brasileira. Cad. Saúde Pública, Rio de Janeiro, v. 27, n. 1, p. 7-18, jan. 2011. Doi: 10.1590/S0102-311X2011000100002.

HARZHEIM, E.; MENDONÇA, C. S. Estratégia Saúde da Família. In: DUNCAN, B. B. et al (org). Medicina ambulatorial: condutas de atenção primária baseadas em evidências. Porto Alegre: Artmed, 2013. p. 32-42.

JUSTINO, A. L. A.; OLIVER, L. L.; MELO, T. P. Implantação do Programa de Residência em Medicina de Família e Comunidade da Secretaria Municipal de Saúde do Rio de Janeiro, Brasil. Ciência \& Saúde Coletiva, Rio de Janeiro, v. 21, n. 5, p. 1.471-1.480, 2016. Doi: 10.1590/1413-81232015215.04342016.

LOPES, J. M. C. Método de abordagem centrada na pessoa. In: Sociedade Brasileira de Medicina de Família e Comunidade. Augusto, D. K.; UMPIERRE, R. N. (org.). PROMEF Programa de Atualização em Medicina de Família e Comunidade: Ciclo 10. Porto Alegre: Artmed Panamericana. 2015. p. 9-45. (Sistema de Educação Continuada a Distância, v. 2). 
MILANEZ, T. C. M. et al. Satisfação e insatisfação na Estratégia Saúde da Família: potencialidades a serem exploradas, fragilidades a serem dirimidas. Cad. Saúde Colet., Rio de Janeiro, v. 26, n. 2, p. 184-190, 2018. Doi: 10.1590/1414-462X201800020246.

PEREIRA, D. F. F.; PEREIRA, E. T. Revisitando a história da educação popular no Brasil: em busca de um outro mundo possível. Revista HISTEDBR On-line, Campinas, n. 40, p. 72 89, 2010. Doi: /10.20396/rho.v10i40.8639807.

PEGORARO, P. B. B.; SCHAEFER, R.; ZOBOLI, E. L. C. P. Desgaste psíquico-moral nos trabalhadores da atenção primária. Rev. Esc. Enferm. USP, São Paulo, v. 51, e03257, 2017. Doi: 10.1590/S1980-220X2016035203257.

SOCIEDADE BRASILEIRA DE MEDICINA DE FAMÍLIA E COMUNIDADE. Currículo Baseado em Competências para Medicina de Família e Comunidade. 2015. Doi: 10.5712/rbmfc10(34)1105.

SORATTO, J. et al. Insatisfação no trabalho de profissionais da saúde na Estratégia Saúde da Família. Texto Contexto Enferm., Florianópolis, v. 26, n. 3, set. 2017. Doi: 10.1590/010407072017002500016.

STARFIELD, B. Atenção primária: equilíbrio entre necessidades de saúde, serviços e tecnologias. Brasília: UNESCO; MS, 2002.

STEWART, M. Patient-centered medicine: transforming the clinical method. 3. ed. Abingdon: United Kingdom: Redcliffe Medical, 2014.

VASCONCELOS, E. M. Educação popular e atenção à saúde da família. 6. ed. São Paulo: Hucitec, 2015.

VASCONCELOS, E. M. Educação popular: de uma prática alternativa a uma estratégia de gestão participativa das políticas de saúde. PHYSIS: Rev. Saúde Coletiva, Rio de Janeiro, v. 14, n. 1, e2500016, 2004. Doi: 10.1590/S0103-73312004000100005.

VASCONCELOS, E. M. Educação Popular na Universidade. In: VASCONCELOS, E. M.; CRUZ, P. J. S. C. (Org). Educação popular na formação universitária: reflexões com base em uma experiência. João Pessoa: Editora Universitária da UFPB, 2011. Doi: 10.1590/010407072017002500016.

VASCONCELOS, E. M; PRADO, E.V. (org.). A saúde nas palavras e nos gestos: reflexões da rede de educação popular e saúde. 2. ed. São Paulo: Hucitec, 2017.

VASCONCELOS, E. M.; VASCONCELOS, M. O. D. Educação popular. In: GUSSO, G.; LOPES, J. M. C. (org.). Tratado de medicina de família e comunidade: princípios, formação e prática. Porto Alegre: Artmed, 2012. p. 91-97.

Submetido em 11 de março de 2019.

Aprovado em 24 de abril de 2019. 